\title{
Measurement of atmospheric deposition of polychlorinated dibenzo-p-dioxins and dibenzofurans in the Lagoon of Venice, Italy.
}

\author{
S. Guerzoni ${ }^{a^{*}}$, P. Rossini ${ }^{\text {b }}$, E. Molinaroli ${ }^{\mathrm{c}}$, G. Rampazzo ${ }^{\text {c }}$, S. Raccanelli ${ }^{\mathrm{d}}$ \\ ${ }^{a}$ CNR - Istituto di Biologia del Mare, Riva VII Martiri 1364/A, 30122 Venezia, Italy \\ and Istituto di Geologia Marina, via Gobetti 101, 40129 Bologna, Italy \\ ${ }^{b}$ Terra-Centro Studi Ambientali, Via al Torrente 22, 47037 Rimini, Italy \\ ${ }^{c}$ Dipartimento di Scienze Ambientali, Università di Venezia, Dorsoduro 2137, 30123 Venezia, Italy \\ ${ }^{d}$ INCA, via della Libertà 5/12, 30175 Marghera-Venezia, Italy
}

\begin{abstract}
Data on atmospheric fall-out of polychlorinated dibenzo-p-dioxins (PCDDs) and dibenzofurans (PCDFs) were provided by collecting bulk deposition in four stations inside the Lagoon of Venice. A total of 44 monthly samples was collected during the period July 1998 - July 1999 in one site near an industrial area (Porto Marghera), one site in the city of Venice, and two sites in the southern- and northernmost ends of the Lagoon. Fluxes of PCDD/Fs were between 0.1 and $470 \mathrm{pg} \mathrm{m}^{-2} \mathrm{~d}^{-1}$, corresponding to 0-9.2 $\mathrm{pg}$ of 2,3,7,8-TCDD equivalents (TEQ) $\mathrm{m}^{-2} \mathrm{~d}^{-1}$, with a gradient increasing from remote to urban/industrial stations. Thus, annual deposition of PCDD/Fs to the Lagoon (total area $=$ $550 \mathrm{~km}^{2}$ ), calculated with various methods, turned out to be $\sim 12 \mathrm{~g}$, corresponding to $\sim 400 \mathrm{mg}$ TEQ. Significant differences were found among the stations, with a clear fingerprinting signature (PCDF/PCDD>1) of the deposition collected near Porto Marghera, and a reversed pattern $(\mathrm{PCDF} / \mathrm{PCDD}<1)$ in the rest of the Lagoon, which pattern was similar to the sediments collected in the same locations. Lastly, the amount of bulk $\sum$ TEQ of all stations was compared with the guide values for dioxins in depositions proposed by De Fré et al. (2000).
\end{abstract}

Keywords: Atmospheric fall-out; Dioxins; Furans; Porto Marghera; VCM emission; Guidelines.

\section{Introduction}

(*) corresponding author.

E-mail address: stefano.guerzoni@ibm.ve.cnr.it (S: Guerzoni) 
Persistent organic pollutants (POPs) are organic chemicals which are stable to photochemical, chemical and biological decomposition. Most of them would not exist in nature without human activity. POPs are present in the atmosphere in gaseous and aerosol phases. They degrade in the atmosphere as a result of various physical-chemical processes and are removed by wet and dry deposition (UNEP/MAP/WMO, 2001).

Among these substances, dioxins and furans (PCDD-Fs ) are not especially produced, but are formed as interim species (by-products) in the process of certain human activities, i.e. industrial processes, fossil fuel combustion, or waste destruction. Air is the main distribution pathway for PCDD-Fs, and PCDD/F composition is therefore influenced by different emissions and congener/homologue-selective transport and atmospheric loss processes (Lohmann and Jones, 1998).

Much work has been done in the past 20 years, to study the presence of PCDD/Fs and other organic chlorine in bottom sediments and aquatic biota in the Lagoon of Venice, Italy. Sources of the contamination are often discharges from the industrial district of Porto Marghera, untreated domestic sewage from the historical city of Venice, and traffic from motorboats and the nearby city of Mestre (Fattore et al., 1997; Di Domenico et al., 1997; Marcomini et al., 1997; Wenning et al., 2000).

Preliminary available data on atmospheric dioxin fall-out were provided by bulk deposition sampling (Rossini et al., 2001), and a budget of dioxin showed that atmospheric deposition accounted for one-quarter of the total load in the Lagoon of Venice (Marcomini et al., 1999). Data on soils collected around the industrial zone suggested an airborne PCDD/F fall-out effect up to several km downwind (Della Sala et al., 1999).

This paper presents data of 2,3,7,8,-substituted PCDD/Fs in atmospheric fall-out, provided by sampling monthly bulk depositions in four stations inside the Lagoon of Venice $\left(550 \mathrm{~km}^{2}\right)$. The purposes of this study were to detect the influence of the industrial district on PCDD/F deposition, to estimate total fluxes inside the lagoon, and to apply statistical multivariate analyses and modelling in order to detect the principal sources of dioxin and furan. 


\subsection{Sampling}

Atmospheric depositions were collected by 4 bulk samplers similar to those tested by Horstmann and McLachlan (1997) in a rural environment (Figure 1). Bulk samplers were polymer structures formed of a cylindrical container and a protection ring to avoid damage by birds and animals. The structure was clamped to a $60-\mathrm{mm}$ pole. A Pyrex bottle with a funnel properly silanised (treated with dimethyldichlorosilane 5\% in toluene) was placed in the support. Bulk sampling has been extensively used, since these samplers are easier to operate than wet \& dry ones, and can also be located at sites with no electrical power supply. Horstmann and McLachlan (1997) recently found that parallel bulk sampling reproducibility was lower than $10 \%$ in more than $80 \%$ of cases and lower than $20 \%$ in $99 \%$ of cases, and also that the diffusive fraction is small with respect to total deposition. The limitation of this sampling method is mainly possible under-estimation of fluxes because of the limited collection of dry gases which, according to Schröder et al. (1997), are of minor importance for PCDD/Fs. Advantages are the integration of samples over one month and the possibility of large scale application with low-cost equipment.

Figure 1. Bulk deposition sampler (modified from Bergerhoff ${ }^{\circledR}$ ) used in the field. Right: Pyrex ${ }^{\circledR}$ "funnelbottle" unit.

Sampling was carried out monthly during the period July 1998 - July 1999 in one site near an industrial area (Porto Marghera) (Site D), one in the city of Venice (Site A), and two sites in the more remote southern (Site C) and northernmost (Site B) ends of the Lagoon (Figure 2).

Figure 2. Location of atmospheric deposition sampling sites. ( $\mathrm{A}=$ city of Venice; $\mathrm{B}=\mathrm{Valle}$ Dogà; $\mathrm{C}=$ Valle Figheri; $\mathrm{D}=$ Dogaletto). Circle encloses industrial area of Porto Marghera.

\subsection{Analytical methods}

Total atmospheric samples were spiked with a series of $15{ }^{13} \mathrm{C}_{12}$-labelled 2,3,7,8 PCDD-F substituted isomers as internal standards, to deliver $25 \mathrm{pg} \mu \mathrm{L}^{-1}$ in a $10-\mu \mathrm{L}$ final volume, and then extracted in a separatory-funnel with dichloromethane. The extracts were transferred to hexane before the clean up treatment. The sample extracts were firstly spiked with ${ }^{37} \mathrm{C}_{4}$-labeled 2,3,7,8 PCDD (EDF6999 and then cleaned up using an automatic system, Dioxin Prep (Fluid Management System Inc.). All solvents (n- 
hexane, dichloromethane, acetone, toluene, ethylacetate) were Picograde ${ }^{\circledR}$ reagent grade (Pomochem GmbH, Wesel, D). Extraction and clean-up procedures are extensively described in Rossini et al. (2001).

HRGC/HRMS analyses were conducted using a HP 6890 plus gas chromatograph coupled to a Micromass Autospec Ultima mass spectrometer, operating in EI mode at $35 \mathrm{eV}$ and with a resolution of 10.000 (5\% valley). Quantitative determination of PCDD-Fs was performed by an isotope dilution method, using relative response factors previously obtained from five standard solution injections (EDF 9999, Cambridge Isotope Laboratories, Woburn, MA), as recommended by the US-EPA (1994). At the beginning of each day of analysis, GC/MS system performance was verified for all PCDD-Fs and labelled compounds with the CS3 calibration verification standard and the isomer specificity test standard. Two ${ }^{13} \mathrm{C}_{12}$-labeled PCDD (EDF5999) were added to the extract before injection for recovery calculations. Recovery was always in the range $50-110 \%$. Reproducibility did not exceed $20 \%$.

\section{Results and discussion}

\subsection{Meteorology}

During the study period the main wind direction observed was NE-N, with mean wind speed of 2-4 $\mathrm{m} \mathrm{s}^{-}$ ${ }^{1}$, in agreement with the general anemometry of the area (Carrera et al., 1995). In particular, the main wind direction in site $\mathrm{A}$ has been from NE, and the observed frequency for winds from $\mathrm{W}$ was always $<10 \%$ for each deposition sample. Moreover, also the percentage of winds from $\mathrm{N}$ at site $\mathrm{C}$ has been always $<10 \%$. This confirms that these sampling stations have never been downwind from the industrial zone (located NW from site A and $\mathrm{N}$ from $\mathrm{C}$ ).

The rain amount recorded during the study period fell in the variability range known for the area. No correlations have been observed between precipitations and PCDD-Fs deposition.

\subsection{Deposition of PCDD/Fs}

Table 1 presents a comprehensive list of PCDD/F data measured in bulk deposition. In general, fluxes of the sum of tetra- to octa-CDD/F homologues in bulk samples are between 0 and $470 \mathrm{pg} \mathrm{m}^{-2} \mathrm{~d}^{-1}(0-9.2 \mathrm{pg}$ TEQ $\left.\mathrm{m}^{-2} \mathrm{~d}^{-1}\right)$. As expected, there is a gradient, increasing from remote to urban/industrial stations. PCDD/F concentrations for the sum of the tetra through octa-PCDD/F homologues (and the $\sum \mathrm{TEQ}$ ) are as follows: 
$\sim 100 \mathrm{pg} \mathrm{m}^{-2} \mathrm{~d}^{-1}\left(\sum \mathrm{TEQ} \sim 2 \mathrm{pg} \mathrm{m}^{-2} \mathrm{~d}^{-1}\right)$ near the industrial district of Porto Marghera (station D), $\sim 50 \mathrm{pgm}^{-2} \mathrm{~d}^{-1}$ in the city of Venice (station A), and $\sim 30 \mathrm{pgm}^{-2} \mathrm{~d}^{-1}$ in the rest of the Lagoon.

The relations between characteristic grain-size classes of aerosol $(<2 \mu \mathrm{m}, 2-8 \mu \mathrm{m}, 8-32 \mu \mathrm{m},>32 \mu \mathrm{m})$ (Guerzoni et al., 1999) and PCDD-Fs deposition have been investigated, and no significant correlation was observed.

The relative contribution of OCDD to the sum of tetra- to octa- CDD/F homologue groups differs widely among stations and monthly samples, from $\sim 2$ to $\sim 50 \%$. Deposition is in general dominated by the higher chlorinated congeners and, on average, OCDD accounts for $\sim 30 \%$ of the $\mathrm{PCDD} / \mathrm{F}$ flux in stations A,B and C, and for only $15 \%$ near the industrial station D, thus confirming the data from other industrial districts in Austria (Christmann et al. 1989) and elsewhere (Lohmann and Jones, 1988). Possible enhancement of the relative abundances of high-chlorinated dioxins/furans may be due to the dominance of this fraction in the particle phase, whereas the gas phase is dominated by low-chlorinated ones (Oh et al., 2001). Conversely, Jones and Duarte-Davidson (1997) found that the mixture of PCDD/F congeners and homologues was the same in air and in bulk deposition, over given sampling periods and sites. Thus, it was suggested that PCDD/Fs of different levels of chlorination were transferred with similar efficiencies from the air to the collectors, despite different gas/particle partitioning in the air.

The PCDD:PCDF ratio in the deposition also varies, ranging from 0.1 to 4.7 . The mean value drops from 0.5 in site D, near Porto Marghera, to 1.7 in the city of Venice (site A), with intermediate values around 1 in the two stations at the northern and southern edge of the Lagoon (sites B and C). This inversion in the PCCD:PCDF ratio is also clearly shown in sediments collected near the industrial district (PCDD:PCDF $<0.5$ ), compared with sediments from the channel in the historical centre of Venice, with PCDD:PCDF ratio values $>2$. The difference in the ratio was taken as a sign of different sources affecting the two locations (Marcomini et al., 1999; Wenning et al., 2000).

\subsection{TEQs}

$\sum$ TEQ deposition fluxes are in the range $0-10 \mathrm{pg} \mathrm{m}^{-2}$ per day (mean $\sim 2 \mathrm{pg} \mathrm{m}^{-2} \mathrm{~d}^{-1}$ ), with $2,3,4,7,8$ PeCDD/F contributing, on average, between 20 and $30 \%$ of the STEQ (see Figure 3). Mean deposition 
fluxes in the whole Lagoon of Venice are at the lower end of the ranges found in remote-rural stations, as reviewed by Lohmann and Jones (1998), who have shown a decline in PCDD/F fluxes in Germany and the UK in recent years. Deposition fluxes in stations A (urban) and D (industrial) in the Lagoon of Venice are approximately one-half to on-quarter of those found in Kyoto Bay by Sakai et al. (2001) and are similar to those found in recent years in Hesse, Germany (Fiedler et al. 2000).

Table 1. Atmospheric fluxes of 2,3,7,8-substituted dioxins and furans (P4-8CDD/F) in Lagoon of Venice from July 1998 to July 1999, together with information on other variables. Values below detection limit were considered equal to zero. $*=9$ months sampling (November $1998-$ July 1999). ${ }^{1}=$ TE calculation made using WHO-TEF (Van den Berg et al., 1998).

Figure 3. Relative individual contribution to overall TEQs in deposition

\subsection{PCDD/F total deposition to Lagoon}

Total annual deposition to the entire Lagoon $\left(550 \mathrm{~km}^{2}\right)$ was calculated by a method in which monthly rain and wind isopleths were combined to normalise monthly deposition values (Rossini et al., 2001). PCDD/F total fluxes inside the Lagoon were $\sim 12$ grams, corresponding to $~ 400 \mathrm{mg}$ TEQ. Higher fluxes were calculated for winter (mean Oct.-Feb.: $\Sigma \mathrm{PCDD} / \mathrm{F}$ flux $\sim 40 \mathrm{mg} \mathrm{TEQ} / \mathrm{month}$ ) than summer (mean March-Sept.: $\sum \mathrm{PCDD} / \mathrm{F}$ flux $\left.~ 15 \mathrm{mg} \mathrm{TEQ} / \mathrm{month}\right)$, in line with similar seasonal differences reported by Duarte-Davidson et al. (1994) and Halsall et al. (1997) (Figure 4).

Figure 4. Pattern of monthly $\sum$ PCDD/F deposition (mg TEQ) to the entire Lagoon during study period (July 1998-July 1999).

\subsection{Fingerprinting}

It is instructive to compare the pattern of PCDD/Fs in bulk deposition sampled concurrently in different stations, because this yields information on the relative horizontal transfer of the compounds. Data from the four sampling sites show significant differences, with a clear fingerprinting signature (PCDF $>$ PCDD) in most of the samples collected near the industrial zone.

Comparisons of the PCDD-F patterns of the homologue groups of each monthly sample show high similarity (with some month-to-month variations) between stations A, B and C (Figure 5). In particular, in 
these three stations, $8 \mathrm{CDD}$ (and 7CDD) made the prevailing contribution to $\sum \mathrm{PCDD} / \mathrm{F}$ loading. Instead, station D revealed three different patterns: one (D- $\gamma, 5$ samples) was similar to all samples in stations A, B and $\mathrm{C}$; in the other two patterns (D- $\alpha, 5$ samples, and D- $\beta, 3$ samples) OCDF made a different contribution to $\sum \mathrm{PCDD} / \mathrm{F}$ loading, increasing from $~ 20(\mathrm{D}-\gamma)$ to $\sim 40 \%$ (D- $\beta$ ) and reaching values $>70 \%$ (D- $\alpha$ ), thus reversing the PCDD:PCDF ratio from $<1$ to $\cong 2$. It is interesting to note that, during the last two months of the survey (June and July 1999), all four stations showed a strikingly similar increase in the relative contribution of OCDF to the total PCDD/F loading, possibly related to an accidental release of $900 \mathrm{~kg}$ of vinyl chloride monomer (VCM) from the industrial district.

Figure 5. Comparisons of PCDD/F patterns in bulk deposition. Error bars represent one single standard deviation. Above: stations A,B,C =annual average; station D, monthly samples. Below: site D, monthly samples. [Analytical data normalised to total sum of PCDDs+PCDFs $=1000$ ] (see text $\underline{\text { for details) }}$

\subsection{Multivariate statistics}

Principal components analysis (PCA) is a technique suitable for ordinate data in one, two or three dimensions (linear compounds of correlated variables) and allows to interpret them as factors influencing the data. The method is well described in Le Maitre (1982) and Swan and Sandilands (1995). In this study, PCA was applied to the homologue profiles of dioxins and furans, together with profiles of source-related fingerprints.

Other authors applied multivariate analysis to environmental samples collected in Venice. Among them, Fattore et al. (1997) classified sediments samples of the Venice lagoon and source-related samples from literature, and Jimenez et al (1998) compared sediments from Lagoon of Venice to sediments from another Italian lagoon (Orbetello). Both authors found that patterns of samples collected near Porto Marghera and in the Central lagoon were very similar to sediments affected by the production of ethylene dichloride (EDC) and polyvinyl chloride (PVC), whereas the profiles of most of the other samples were similar to those of sewage sludge, gasoline and diesel engine emissions. Finally PCA of dioxin and furans patterns in sediments and biota (Wenning et al., 2000) indicated that the composition of PCDD/Fs in sediments was generally different from those in fish and shellfish. 
In order to compare deposition profiles of samples collected in this study with those arising from environmental sources of pollutants, results obtained by other authors on different kinds of samples were also inserted into the processing, together with data from samples from the Venice industrial district (Table 2). In detail, these markers include: (a) "urban" and "rural" aerosol samples (Cole et al., 1999); (b) wastewater and sludge derived from PVC production processes (Stringer et al., 1995); (c) solid waste and sludge from production of EDC, VCM and PVC in the USA (Carrol et al., 1996). To this, we added data derived from direct analysis of wastewater from EDC, sludge from the industrial district of Porto Marghera (EDC, VCM and PVC production), and wastewater from two municipal water treatment plants (Fusina and Campalto, near Venice).

Table 2. Source-related samples used for principal component analysis. EDC=ethylene dichloride, $\underline{\mathrm{VCM}=\text { vinyl chloride monomer, } \mathrm{PVC}=\text { polyvinyl chloride. }}$

PCA was used to take the data from the original 10-dimensional space (PCDD/F homologue profiles) and project them onto a two-dimensional plane that retains most of the information from the original data. Three factors were extracted from the analysis, accounting for $\sim 75 \%$ of total variance (Table 3 ). Factor 1 (F1) is characterised by tetra- to octa-CDF homologues, mainly of industrial origin, and accounts for $38 \%$ of variance. Factor 2 (F2) is influenced by tetra- to hexa-CDD, and represents $23 \%$ of variance. Factor 3 (F3) is influenced by heptachlordibenzodioxins (7CDD) and 8CDD in the positive sense and by $8 \mathrm{CDF}$ in the negative one, and accounts for $15 \%$ of variance.

Table 3. Factor loadings from principal component analysis.

Each monthly deposition sample, together with all markers, can now be plotted in the space of the new variables (factors). As F1 and F3 are factors that better discriminate samples, Figure 6 shows samples ordered in two dimensions (F1, F3), where crosses represent different source-related fingerprints from Table 2.

Figure 6. Plot of samples and markers in dimensional space of factor 1 and factor 3 , derived from Principal Components Analysis, applied to homologue profiles of dioxins and furans. 
All samples with higher levels of octa-CDF and lower ones of octa-CDD plot in the lower part of the graph plot (solid line). As the figure shows, all industrial markers (i.e., EDC-, VCM-, PVC-related samples) plot in this area (Figure 6, Table 2). Several deposition samples, mainly from site D -i.e. those with $\alpha$ and $\beta$ fingerprints- fall in this part of the plot, together with two samples collected in July 1999 in the city of Venice (site A) and in the southern part of the Lagoon (site C). The second area (dotted line), in the higher part of the plot, includes samples with low levels of octa-CDF and higher contents of hepta- and octa-CDD, together with the markers of civil water treatment plants, urban and rural aerosols. This area includes most of the A, B, C and D- $\gamma$ patterns. Briefly, station D, near the industrial zone, is typically influenced by atmospheric emissions of dioxins and furans enriched in OCDF, probably associated with VCM production. The source of emission also occasionally contaminates atmospheric deposition of such substances in the other sites.

\subsection{Comparisons with guidelines}

Emission into the atmosphere followed by deposition on plants and animal uptake is the main pathway of human exposure to dioxin. The World Health Organisation states that the tolerable daily intake (TDI) of dioxins for humans is 1-4 pg TEQ $\mathrm{kg}^{-1} \mathrm{day}^{-1}$. By means of selected transfer models (Prinz et al., 1993), daily intake values have been translated into quality objectives for dioxin deposition, and the Flemish Institute for Technological Research (VITO) deduced a target value for dioxin deposition of 3.4-13.6 pg TEQ $\mathrm{m}^{-2}$ day $^{-1}$ (De Fré et al., 2000). More recently, the European Union strategy on PCDD-Fs and polychlorobiphenyls (PCBs) has aimed at reducing human intake levels to $14 \mathrm{pg}$ TEQ $\mathrm{kg}^{-1}$ week $^{-1}$ (European Commission, 2001, EU strategy on dioxins, furans and polychlorobiphenyls), corresponding to $\sim 7$ pg TEQ $\mathrm{m}^{-2}$ day $^{-1}$.

On this basis, the frequency of all bulk deposition samples collected in the four stations exceeding the guidelines was calculated (Figure 7). Although the actual atmospheric deposition of dioxins and furans in Venice is not very high, one sample exceeds the deposition value based on the EU target value for human intake. But, as was reported in a previous work (Rossini et al., 2001), in a more realistic exposure scenario, mixtures of dioxin-like and non-dioxin-like compounds should also be considered. For example, Van 
Birgelen (1998) reports that hexachlorobenzene (HCB) should be classified as a dioxin-like compound, as its mechanism of action resembles that of mono-ortho-substituted PCBs. According to the limited information available, it is estimated that HCB is about 10,000 times less potent than TCDD, corresponding to a relative potency value of 0.0001 (Van Birgelen, 1999).

Lastly Figure 7 shows the frequency of samples exceeding the guidelines, adding TEQs due to PCBs and $\mathrm{HCB}$ to PCDD/F values (recalculated from Rossini et al., 2001). In this way, $9 \%$ of samples exceed the limit value, $16 \%$ exceed the EU target value, and $27 \%$ exceed the guide value (PCDD-F+PCB+HCB curve). Samples exceeding the limit value were collected in July 1998 and October and February 1999, in sites A and D.

Figure 7. Cumulative frequency of samples exceeding guidelines (recalculated from Rossini et al., 2001). ${ }^{1}$ De Fré et al., 2000, ${ }^{2}$ European Commission, 2001, EU strategy on dioxins, furans and polychlorobiphenyls.

\section{Conclusions}

- Bulk deposition provided one-year of data on PCDD/F fluxes, which were independent of rainfall and particle grain-size;

- Dioxin and furan fluxes from the atmosphere in the Lagoon of Venice were generally lower than those found in Kyoto Bay and similar to those in Hesse, Germany;

- PCA was used to compare differing PCDD/F patterns among stations, which may indicate different sources;

- The station D nearest the industrial zone showed signs of contamination from EDC and VCM production;

- Between $9 \%$ and $27 \%$ of the samples exceed the integrated guide-line values, recently proposed by the Flemish Institute for Technological Research.

\section{Acknowledgements}


This work was carried out on behalf of the Water Management Authority of Venice, within the framework of actions for safeguarding the Lagoon of Venice (art. 3, L.798/1984 - project Orizzonte 2023). Ms Gabriel Walton revised the English text. This is IGM-CNR scientific contribution No. 1279

\section{References}

Carrera F., Cerasuolo M. Tomasin A., Canestrelli P., 1995. La nebbia a Venezia nel quarantennio 19511990. Analisi comparata degli andamenti di visibilità, pressione, temperatura e vento. Istituto Veneto di Scienze, Lettere ed Arti, Rapporti e Studi 12, 235-271.

Carroll, Jr. W. F., Borrelli F. E., Garrity P.J., Jacobs R. A., Ledvina J., Lewis J. W., McCreedy R. L., Weston A. F., 1996. Characterisation of emissions of dioxins and furans from ethylene dichloride (EDC), vinyl chloride (VCM) and polyvinylchloride (PVC) facilities in the United States.

Organohalogen Compounds 27, 62-69.

Christmann W., Klöppel K.D., Partscht H., Rotard W., 1989. Determination of PCDD/PCDF in ambient air. Chemosphere 19, 521-526.

Cole J.G., MacKay D., Jones K.C. Alcock R.E., 1999. Interpreting, correlating and predicting the multimedia concentrations of $\mathrm{PCDD} / \mathrm{Fs}$ in the United Kingdom. Environmental Science \& Technology 33, 399-405.

De Fré R., Cornelis C., Mensink C., Nouwen J., Schoeters G., Roekens, E., 2000. Proposed limit values for dioxin deposition in Flanders. Organohalogen Compounds 45, 324-327.

Della Sala S., Scazzola R., Terrabujo C., Giandon P., Wenning R., Dodge D.G., Luksembur W.J., Weagraff S.A., 1999. Assessment of PCDD/Fs, PCBs, and heavy metals in soil: a measure of the impact of the industrial zone of Porto Marghera on inland coastal areas of Italy. Organohalogen Compounds 43, 137-142.

Di Domenico, A., Baldassarri, L.T., Ziemacki, D., De Felip, E., Ferri, F., Iacovella, M., La Rocca, C., Rodriguez, F., Volpi, F., Ferrari, G., Sansoni, R., Settmo, G., 1997. Selected carcinogenic organic microcontaminants and havy metals in the Venice Lagoon. Organohalogen Compounds 34, 54-60.

Duarte-Davidson R., Clayton P., Coleman P., Davis B.J., Halsall C.J., Harding-Jones P., Pettit K., Woodfield M.J., Jones K.C., 1994. Polychlorinated dibenzo-p-dioxins (PCDDs) and furans (PCDFs) 
in urban air and deposition in the UK. Environmental Science and Pollution Research 1, 262-270.

Fattore, E., Benfenati, E., Mariani, G.,Fanelli, R., Evers, E.H.G, 1997. Patterns and sources of

polychlorinated dibenzo-p-dioxins and dibenzofurans in sediments from the Venice Lagoon, Italy.

Environmental Science \& Technology 31, 1977-1984.

Fiedler H., Rottler H., Peichl L., Knetsch G., Basler A., 2000. Concentrations of PCDD/PCDF in atmospheric samples in Germany. Organohalogen Compounds 45, 264-268.

Guerzoni S., Molinaroli E., Rossini P., Rampazzo G., Quarantotto G., De Falco G., Cristini S., 1999. Role of desert aerosol in metal fluxes in the Mediterranean area. Chemosphere 39, 229-246.

Halsall C.J., Coleman P.J., Jones K.C., 1997. Atmospheric depositions of polychlorinated dibenzo-pdioxins / dibenzofurans (PCDD/Fs) and polycyclic aromatic hydrocarbons (PAHs) in two UK cities. Chemosphere 35, 1919-1931.

Horstmann M., McLachlan M.S., 1997. Sampling bulk deposition of polychlorinated dibenzo-p-dioxins and dibenzofurans. Atmospheric Environment 31, 2977-2982.

Jimenez, B., Fossi, M.C., Gonzales, M.J., Elijarrat, E., Rivera, J., 1998. PCDDs and PCDFs in crabs and sediments from the Venice Lagoon, Italy. Environmental Science \& Technology 32, 3853-3861.

Jones K.C., Duarte-Davidson R., 1997. Transfer of airborne PCDD/Fs to bulk deposition collectors and herbage. Environmental Science \& Technology 31, 2937-2943.

Le Maitre, R.W., 1982. Numerical petrology: statistical interpretation of geochemical data. Elsevier, Amsterdam.

Lohmann R., Jones K.C., 1998. Dioxins and furans in air and deposition: a review of levels, behaviour and processes. The Science of the Total Environment 219, 53-81.

Marcomini, A., Zanette, M., D'Andrea, F., Dalla sala, S., 1997. Diossine, ambiente e salute, Arsenale Editrice, Venezia (in Italian)

Marcomini A., Bonamin V., Degetto S., Giacometti A., 1999. Occurrence of organochlorine pollutants in three dated sediment cores from the lagoon of Venice. Organohalogen Compounds 43, 373-382.

Oh J.E., Choi J.S, Chang Y.S., 2001, Gas/particle partitioning of polychlorinated dibenzo-p-dioxins and dibenzofurans in atmosphere. Evaluation of predicting models. Atmospheric Environment 35, 41254134. 
Prinz, B., Krause, G., Rademacher, L., 1993. Standards and guidelines for PCDD/F. An integrated approach with special respect to the control of ambient air pollution. Chemosphere 27, 491-500.

Rossini P., De Lazzari A., Guerzoni S., Molinaroli E., Rampazzo G., Zancanaro A., 2001. Atmospheric input of organic pollutants to the Venice lagoon. Annali di Chimica 91, 491-501.

Sakai, S.I., Hayakawa, K., Takatsuki, H., Kawakami, I., 2001. Dioxin-like PCBs released from waste incineration and their deposition flux. Environmental Science \& Technology 35, 3601-3607.

Schröder J., Welsch-Pausch K., McLachlan M.S., 1997. Measurements of atmospheric deposition of polychlorinated dibenzo-p-dioxins (PCDDs) and dibenzofurans (PCDFs) to a soil. Atmospheric Environment 31, 2983-2989.

Stringer R.L., Costner P., Johnston P.A., 1995. PVC manufacture as a source of PCDD/Fs. Organohalogen Compounds 24, 119-123.

Swan, A.R.H., Sandilands, M., 1995. Introduction to geological data analysis. Blackwell Science, Oxford.

UNEP/MAP/WMO, 2001. Atmospheric input of persistent organic pollutants to the Mediterranean Sea. MAP Technical Report Series, 130, UNEP/MAP, Athens.

US EPA, 1994. Method 1613B/94: Tetra-Through Octa-Chlorinated Dioxins and Furans by Isotope Dilution HRGC/HRMS.

Van Birgelen A.P.J.M., 1998. Hexachlorobenzene as a possible major contributor to the dioxin activity of human milk. Environmental Health Perspectives 106, 683-688.

Van Birgelen A.P.J.M., 1999. Hexachlorobenzene is also a dioxin-like compound: possible impact on the TEQ. Organohalogen Compounds 44, 509-512.

Van Den Berg M., Birbaum L.S., Bosveld B.T.C., Brunstrom B., Cook P., Feeley M., Giesy J.P., Hanberg A., Hasegawa R., Kennedy S.W., Kubiak T., Larsen J.C., Van Leeuwen F.X.R., Liem A.K.D., Nolt C., Petersen R.E., Poellinger L., Safe S., Schrenk D., Tillit D., Tysklind M., Younes M., Waern F., Zacharewsky T., 1998. Toxic equivalency factors (TEFs) for PCBs, PCDDs for humans and wildlife. Environmental Health Perspective 106, 775-779.

Wenning R., Dodge D., Peck B., Shearer K., Luksemburg W., Della Sala S., Scazzola R., 2000. Screeninglevel ecological risk assessment of polychlorinated dbenzo-p-dioxins and dibenzofurans in sediments and aquatic biota from the Venice Lagoon, Italy. Chemosphere 40, 1179-1187. 



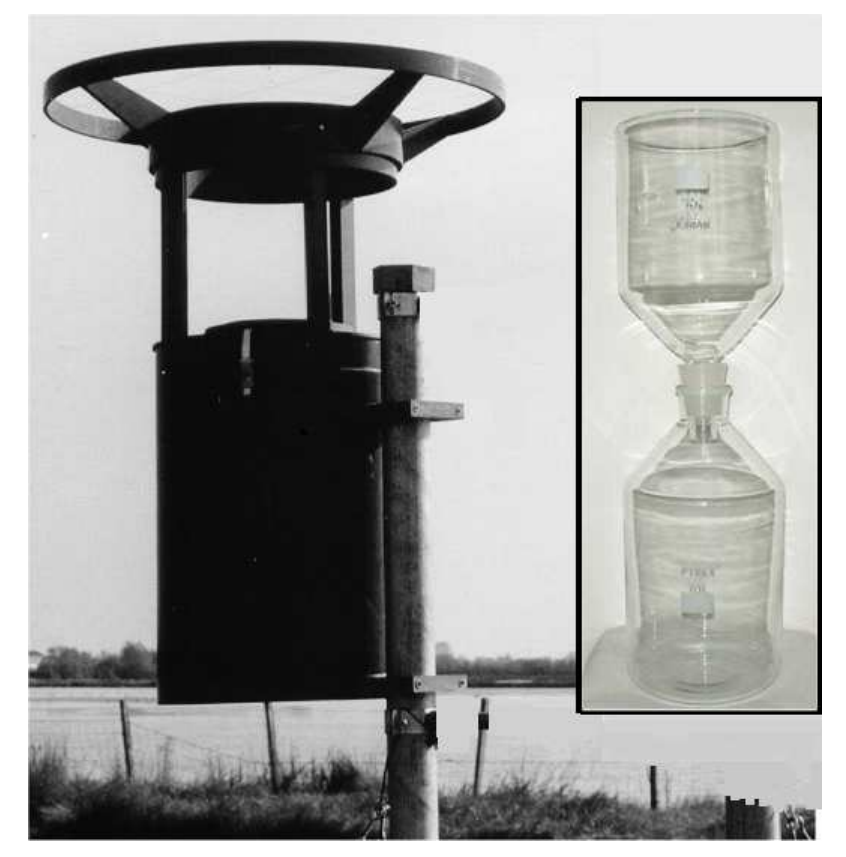




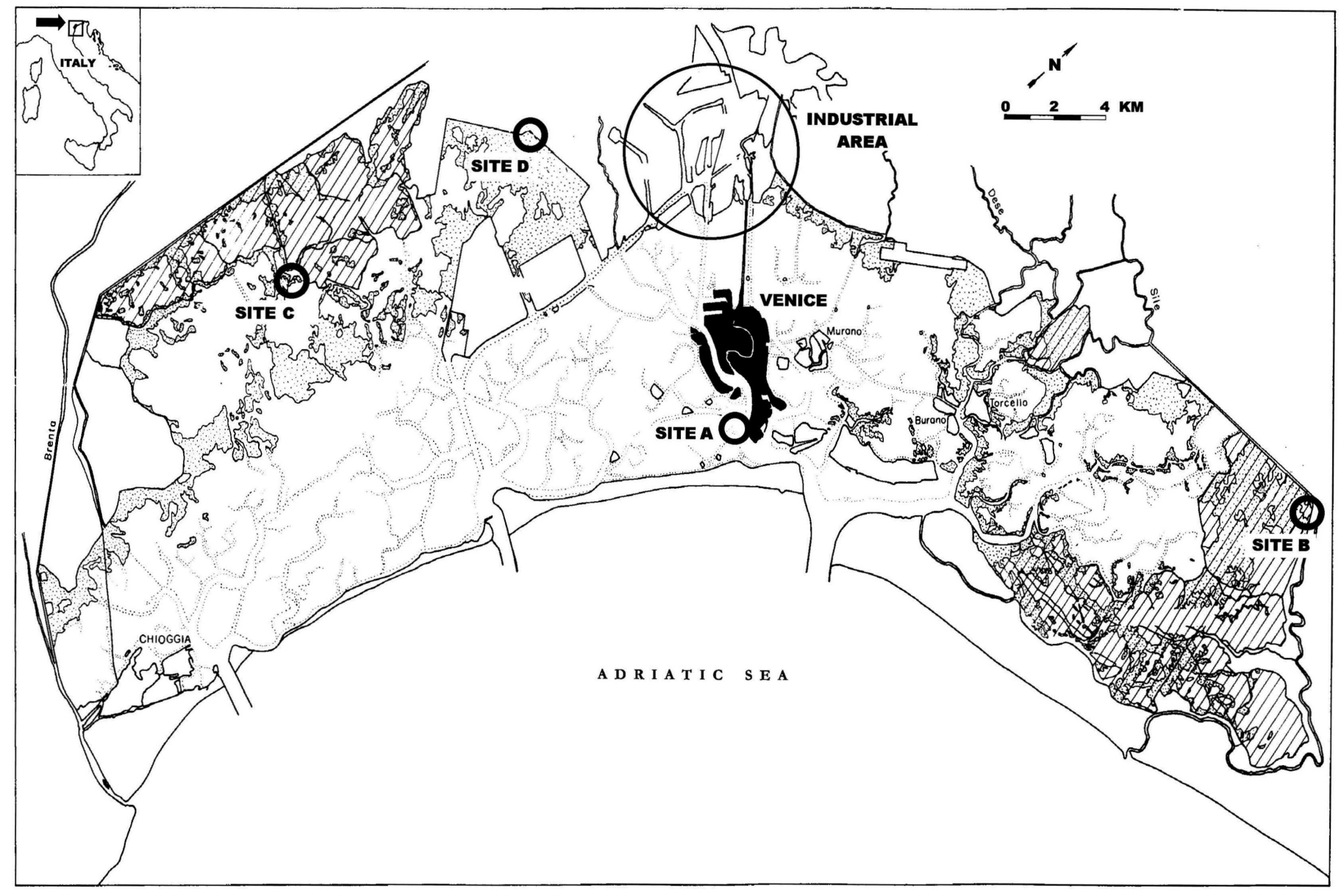




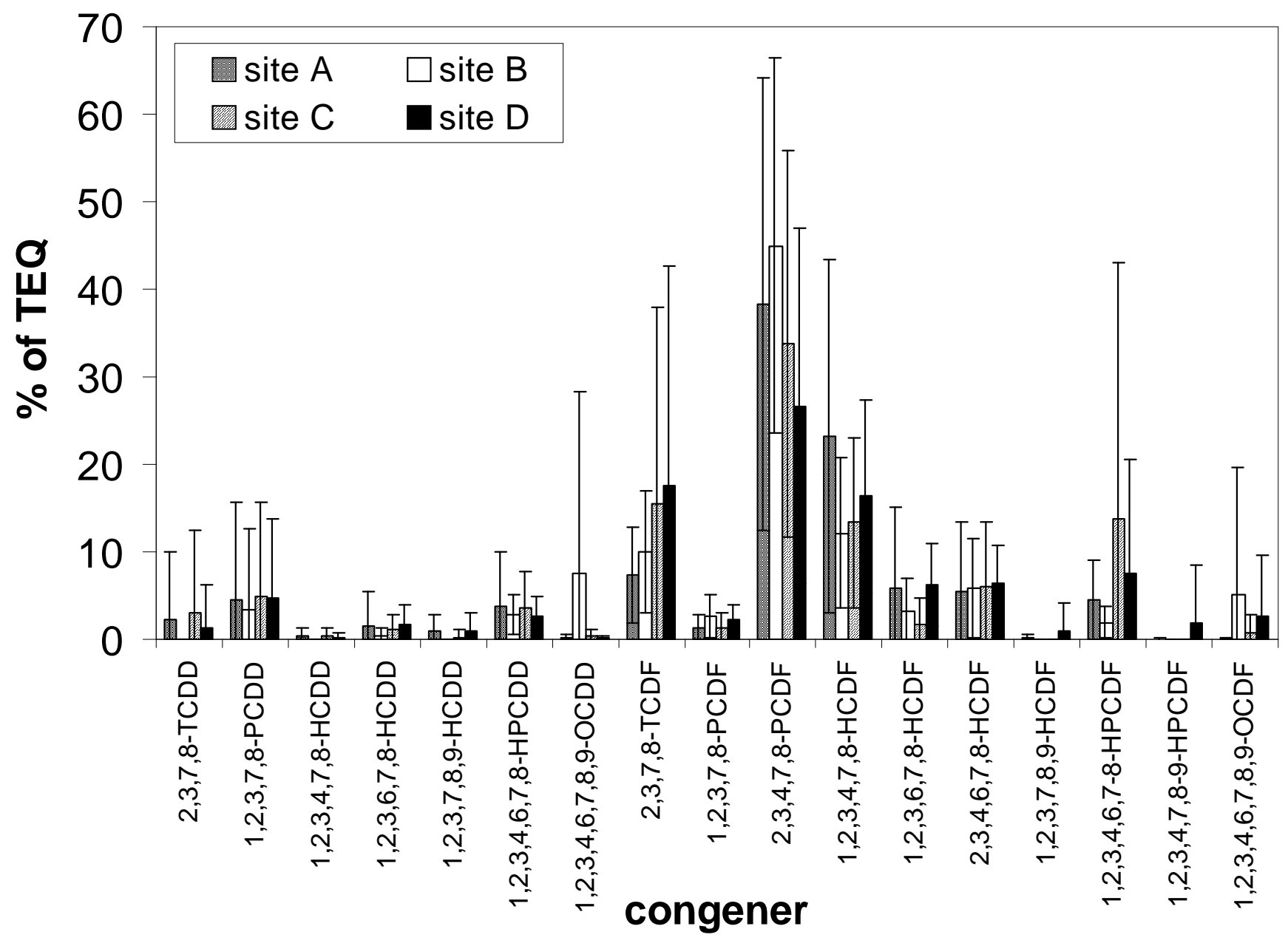




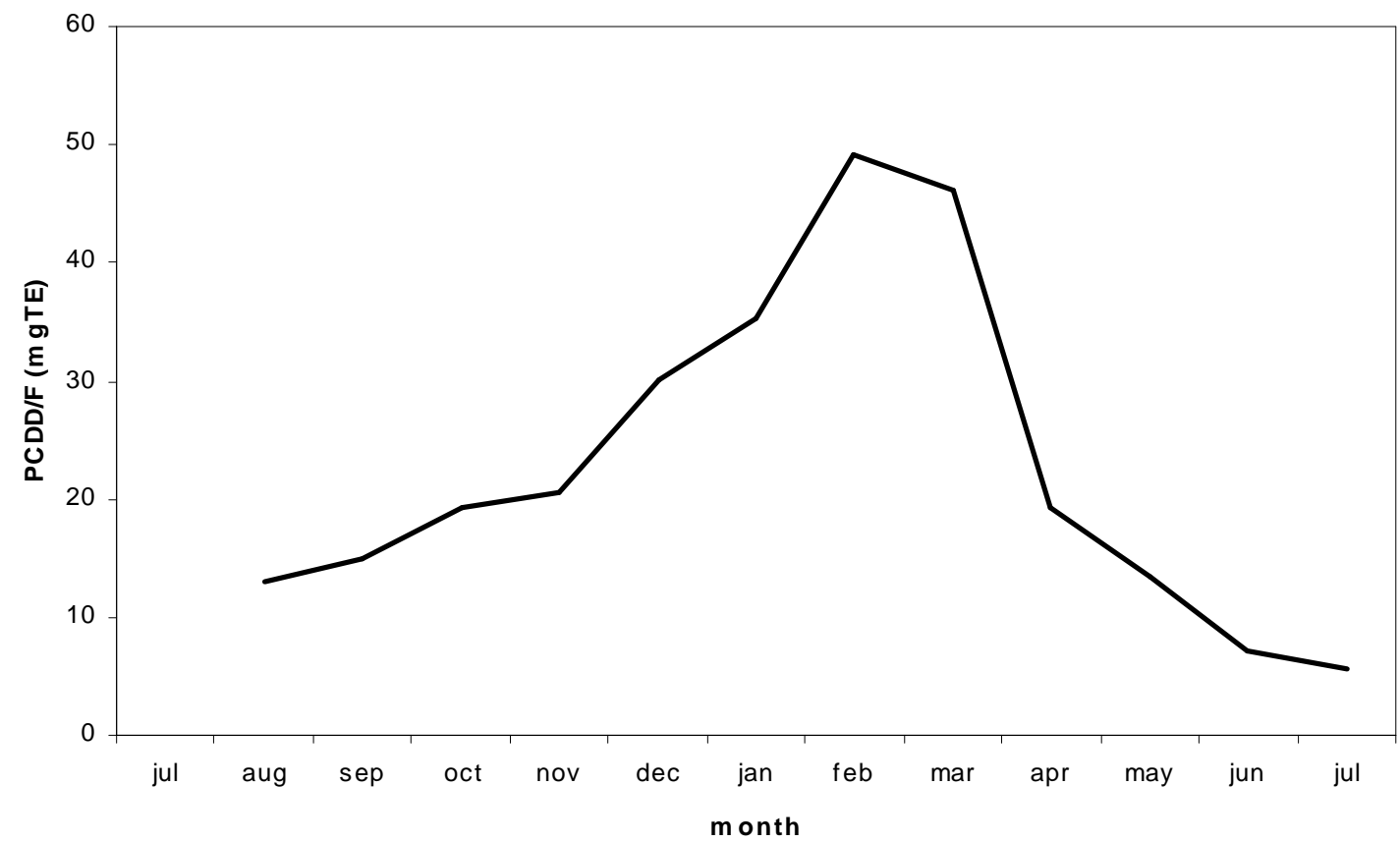



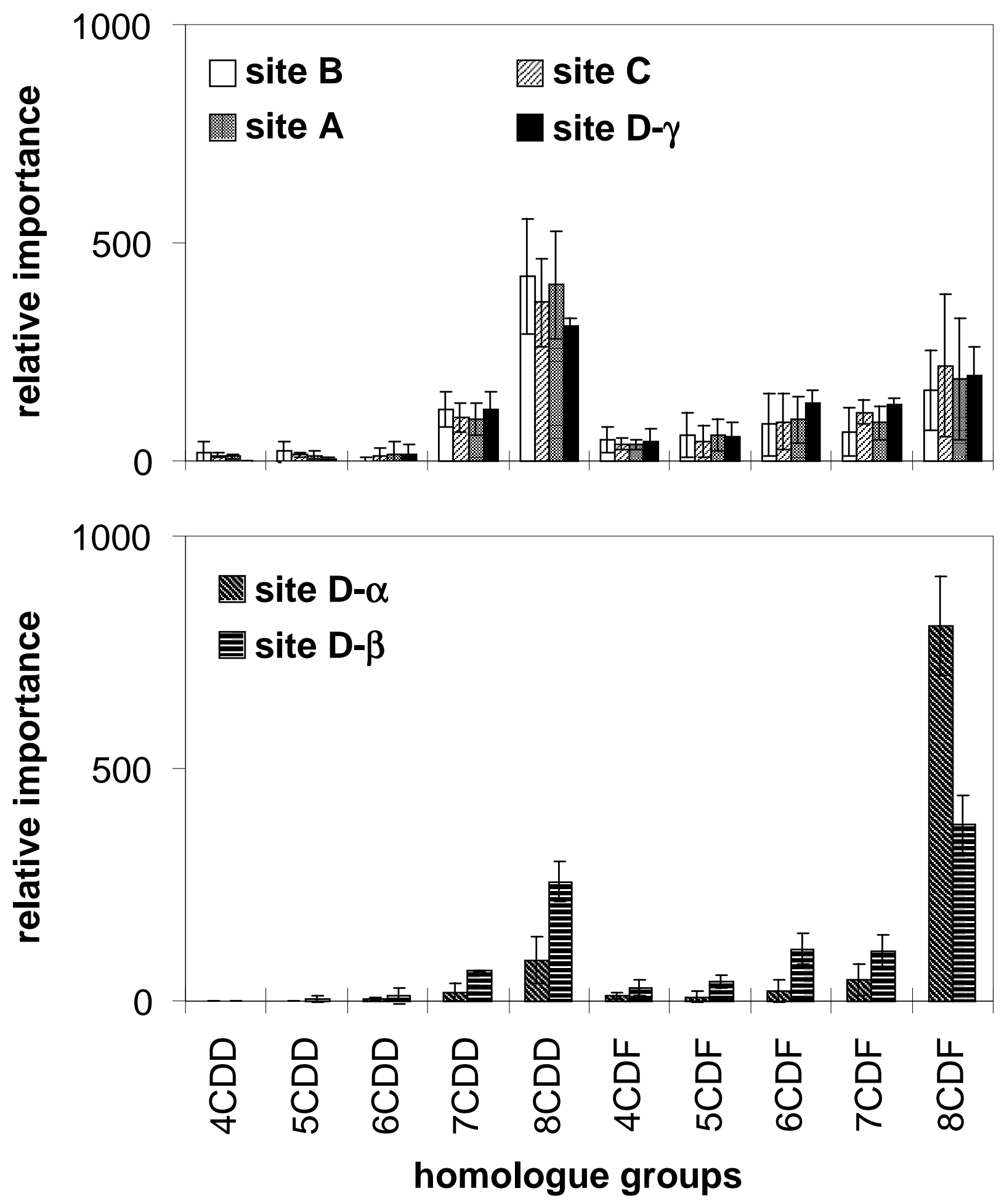


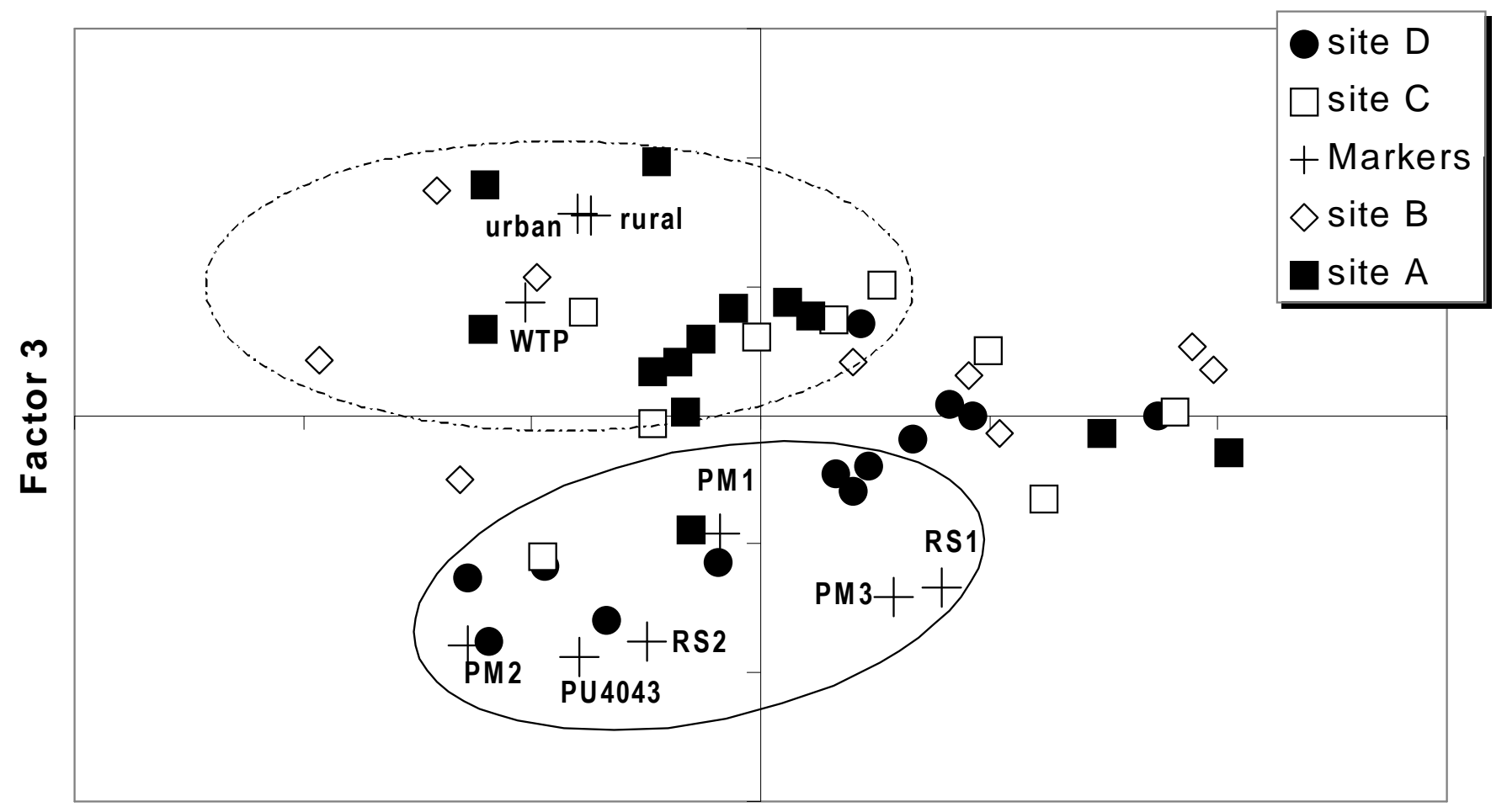

Factor 1 


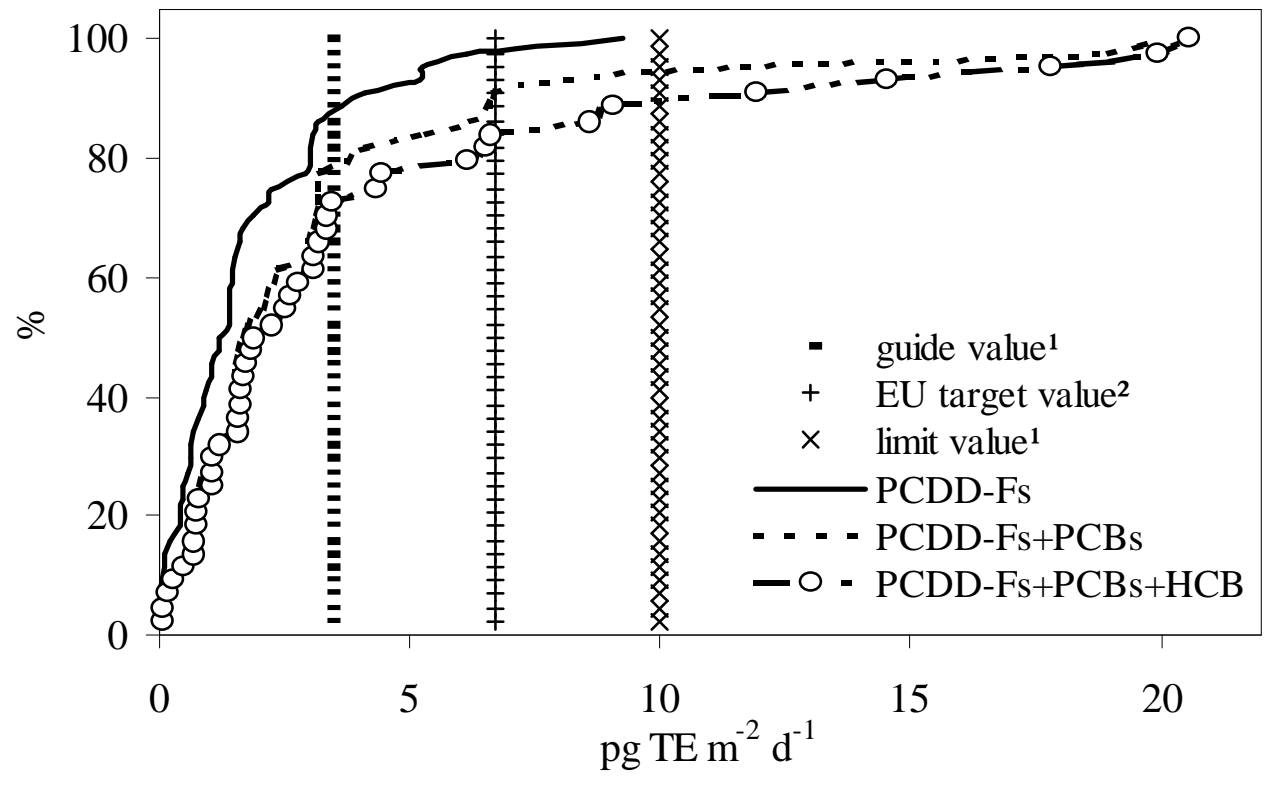




\section{Figure captions}

Figure 1. Bulk deposition sampler (modified from Bergerhoff ${ }^{\circledR}$ ) used in the field. Right: Pyrex ${ }^{\circledR}$ "funnelbottle" unit.

Figure 2. Location of atmospheric deposition sampling sites. $(A=$ city of Venice; $B=$ Valle Dogà; $C=V$ alle Figheri; D=Dogaletto). Circle encloses industrial area of Porto Marghera.

Figure 3. Relative individual contribution to overall TEQs in deposition.

Figure 4. Pattern of monthly $\sum$ PCDD/F deposition (mg TEQ) to the entire Lagoon during study period (July 1998-July 1999).

Figure 5. Comparisons of PCDD/F patterns in bulk deposition. Error bars represent one single standard deviation. Above: stations A,B,C =annual average; station D, monthly samples. Below: site D, monthly samples. [Analytical data normalised to total sum of PCDDs+PCDFs = 1000] (see text for details)

Figure 6. Plot of samples and markers in dimensional space of factor 1 and factor 3, derived from Principal Components Analysis, applied to homologue profiles of dioxins and furans.

Figure 7. Cumulative frequency of samples exceeding guidelines (recalculated from Rossini et al., 2001). ${ }^{1}$ De Fré et al., 2000, ${ }^{2}$ European Commission, 2001, EU strategy on dioxins, furans and polychlorobiphenyls. 
Table 1.

Atmospheric fluxes of 2,3,7,8-substituted dioxins and furans $\left(\mathrm{P}_{4-8} \mathrm{CDD} / \mathrm{F}\right)$ in Lagoon of Venice from July 1998 to July 1999, together with information on other variables. Values below detection limit were considered equal to zero. $*=9$ months sampling (November $1998-$ July 1999$) .{ }^{1}=$ TE calculation made using WHO-TEF (Van den Berg et al., 1998).

\begin{tabular}{|c|c|c|c|c|c|c|}
\hline site & units & $\begin{array}{c}\Sigma P_{4-8} \mathrm{CDD} / \mathrm{F} \\
\mathrm{pg} \mathrm{m}^{-2} \mathrm{~d}^{-1}\end{array}$ & $\begin{array}{c}\text { OCDD } \\
\% \text { di } \Sigma P_{4-8} \mathrm{CDD} / \mathrm{F}\end{array}$ & PCDD/PCDF & $\begin{array}{c}\Sigma \operatorname{TEQ}^{1} \\
\operatorname{pg~m}^{-2} \mathrm{~d}^{-1}\end{array}$ & $\begin{array}{c}2,3,4,7,8-\mathrm{CDF} \\
\% \text { di } \Sigma \mathrm{TEQ}\end{array}$ \\
\hline \multirow{4}{*}{$\mathbf{A}$} & average & 48.6 & 33.6 & 1.7 & 2.0 & 27.5 \\
\hline & median & 35.4 & 36.0 & 1.5 & 0.9 & 32.9 \\
\hline & $\min$ & 14.3 & 19.2 & 0.4 & 0.2 & 0.0 \\
\hline & $\max$ & 134.6 & 50.1 & 4.3 & 9.2 & 45.7 \\
\hline \multirow{4}{*}{$\mathbf{B}^{*}$} & average & 29.3 & 29.8 & 1.5 & 1.3 & 28.7 \\
\hline & median & 25.4 & 29.9 & 1.1 & 1.4 & 36.7 \\
\hline & $\min$ & 0.0 & 0.0 & 0.0 & 0.0 & 0.0 \\
\hline & $\max$ & 61.1 & 51.3 & 4.7 & 3.2 & 50.2 \\
\hline \multirow{4}{*}{$\mathrm{C}^{*}$} & average & 37.7 & 27.6 & 1.1 & 1.8 & 24.2 \\
\hline & median & 30.0 & 25.8 & 1.1 & 1.0 & 32.9 \\
\hline & $\min$ & 9.8 & 17.5 & 0.3 & 0.0 & 0.0 \\
\hline & $\max$ & 109.2 & 38.1 & 1.9 & 6.2 & 36.0 \\
\hline \multirow{4}{*}{$\mathbf{D}$} & average & 124.1 & 15.0 & 0.5 & 1.9 & 19.8 \\
\hline & median & 59.3 & 17.1 & 0.5 & 1.6 & 28.3 \\
\hline & $\min$ & 29.0 & 1.7 & 0.0 & 0.0 & 0.0 \\
\hline & $\max$ & 470.0 & 23.2 & 1.2 & 5.2 & 38.4 \\
\hline
\end{tabular}


Table 2.

Source-related samples used for principal component analysis. EDC=ethylene dichloride, VCM=vinyl chloride monomer, PVC=polyvinyl chloride.

\begin{tabular}{clcc}
\hline Code & \multicolumn{1}{c}{ Source-related samples } & Type & Reference \\
\hline urban & urban air & air & Cole et al., 1999 \\
rural & rural air & air & Cole et al., 1999 \\
PU4043 & heavy ends from distillation of VCM & wastewater & Stringer et al., 1995 \\
RS1 & EDC, VCM, PVC production & solid waste & Carrol et al., 1996 \\
RS2 & EDC/VCM production & sludge & Carrol et al., 1996 \\
PM1 & local EDC, VCM and PVC production & wastewater and sludge & this study \\
PM2 & local VCM production & sludge & this study \\
PM3 & local EDC/VCM production & sludge & this study \\
WTP & domestic water treatment plants & wastewater & this study \\
\hline
\end{tabular}


Table 3.

Factor loadings from principal component analysis.

\begin{tabular}{rrrr}
\hline & Factor 1 & Factor 2 & Factor 3 \\
\hline 4CDD & -0.12 & $\mathbf{0 . 8 1}$ & -0.01 \\
5CDD & 0.19 & $\mathbf{0 . 9 0}$ & -0.01 \\
6CDD & 0.14 & $\mathbf{0 . 8 8}$ & 0.08 \\
7CDD & 0.30 & 0.14 & $\mathbf{0 . 7 8}$ \\
8CDD & -0.09 & -0.11 & $\mathbf{0 . 9 2}$ \\
4CDF & $\mathbf{0 . 7 3}$ & -0.15 & 0.28 \\
5CDF & $\mathbf{0 . 8 4}$ & 0.18 & 0.20 \\
6CDF & $\mathbf{0 . 9 0}$ & 0.10 & 0.19 \\
7CDF & $\mathbf{0 . 6 8}$ & 0.08 & -0.04 \\
8CDF & -0.39 & -0.07 & $-\mathbf{0 . 8 5}$ \\
Expl. Var. & 37.90 & 22.59 & 14.99 \\
\hline
\end{tabular}

